\title{
INDIVIDUALIDADE E IGUALDADE COMO CHAVES PARA A DEMOCRACIA CRIATIVA
}

Jim Garrison ${ }^{1}$

Resumo

Inspirado em John Dewey, este trabalho discute a ideia de igualdade democrática como mesmice e padronização, e as consequência dessa ideia. De acordo com Dewey, o autor defende que a pseudodemocracia econômica desenvolvida atualmente consiste na derrota da democracia política e social, bem como da genuína democracia econômica, e que a igualdade moral é incomensurável.

Palavras-chave: John Dewey; Democracia; Teoria Moral; Filosofia da Educação.

Abstract

Inspired in John Dewey, this work discusses the idea of democratic equality as meaning sameness and standardization, and the consequences of such idea. According to Dewey, the author defends that the economic pseudo-democracy developed nowadays defeats the social and political democracy as well as genuine economic democracy, and that moral equality is incommensurable.

Keywords: John Dewey; Democracy; Moral Theory; Philosophy of Education.

1 Jim Garrison - Professor da Virginia Polytechnic Institute/Blacksburg, EUA E-mail: wesley@vt.edu 



\section{INDIVIDUALIDADE E IGUALDADE COMO CHAVES PARA A DEMOCRACIA CRIATIVA ${ }^{2}$}

"A mesma lei para o leão e para o boi é opressão"

William Blake (1793/1988, 44).

Todo semestre eu ministro um curso típico sobre os aspectos sociais, culturais e econômicos da educação. Geralmente começamos a aula discutindo sobre reprodução. Eu diferencio a reprodução biológica, a transmissão de nossa herança genética, da reprodução social e cultural. Essa última reproduz os costumes sociais, as normas de conduta, as práticas sociais, o uso de ferramentas e a linguagem, assim como as crenças e os valores. Ressalto que a educação é o lugar da reprodução cultural antes de distinguir entre escolarização e educação. A educação é onipresente e inevitável; a escolarização é uma atividade institucionalizada geralmente limitada a horários e locais específicos. A escolarização pública está sujeita à regulamentação e ao controle públicos, supostamente para o bem comum. Eu concluo salientando que a educação verdadeiramente democrática busca a igualdade educacional como uma forma de educar indivíduos capazes de criticar e recriar a sociedade, e náo simplesmente de reproduzir o status quo. Surpreendentemente, muitos dos meus alunosprofessores acham intrigante a noção de democracia criativa. Eles presumem que a nossa democracia já foi concluída e que

2 Uma versão anterior e muito mais curta desse artigo será publicada no American Journal of Education. Com quase o dobro de páginas, a versão atual explora muitos temas omitidos no artigo anterior, como "o novo feudalismo", os testes de inteligência, a liberdade, o desenvolvimento de si mesmo, a criatividade, a singularidade humana e a oposiçáo de Dewey à educaçáo profissional compreendida estreitamente. Também são fornecidos alguns exemplos mais práticos.

Educ. foco, Juiz de Fora, v. 20 , n. 1 , 

Jim Garrison

Educ. foco, só precisa ser preservada. Meu artigo surge em decorrência de meus esforços para responder à perplexidade deles.

Vamos nos concentrar nas ideias de mesmice e de padronização. Há uma profunda sabedoria na epígrafe de William Blake acima. Vamos contar com as percepçóes de John Dewey para iluminar essa sabedoria no contexto da democracia criativa. Temos de atacar a própria ideia de padróes iguais para todos como um veículo de igualdade educacional em uma sociedade democrática e, especialmente, em sociedades que possuem tal sistema de escola pública. Argumentarei que a igualdade é a antítese da mesmice, pelo menos no sentido da igualdade democrática, ou o que, por vezes, Dewey chama de “igualdade moral”. A igualdade moral democrática celebra a individualidade qualitativa e incomensuravelmente única a um só tempo. Quando interpretamos a igualdade em termos de mesmice quantitativa e de padróes iguais para todos, ela destrói a igualdade moral democrática enquanto corrompe o ideal de igualdade de oportunidade educacional.

Os padrôes iguais para todos entram na escolarização moderna por meio de sistemas burocráticos e tecnocráticos que assumem sua liderança a partir do mundo dos negócios e da indústria. Esses vários sistemas expressam as necessidades e desejos dos líderes de negócios que os conceberam, e não dos pais, estudantes, professores ou cidadãos. Tais sistemas têm pouco interesse na democracia criativa. Esses modelos também estáo assumindo agora o ensino superior por meio de agências de credenciamento que igualmente tendem a satisfazer os desejos dos líderes de negócios e da indústria, e não dos estudantes, professores e público em geral.

Mais especificamente, eu focalizo a padronização na escolarização. Oscurrículoscontemporâneos, predeterminados, padronizados, iguais para todos e direcionados para objetivos de aprendizagem padronizados, definem a pista em que todos devem correr. Os testes de desempenho padronizados informam a cada suposto indivíduo quem eles são e onde 
eles se encaixam em estruturas sociais predeterminadas, com também com o que eles farão quando chegarem lá.

A maravilhosa concepção industrial do século XIX consistiu no refinamento de recursos naturais em peças padronizadas, portanto facilmente intercambiáveis e substituíveis, para atender à produção nacional. A maravilhosa ideia pós-industrial do século XXI é o refinamento de recursos humanos em peças padronizadas, portanto facilmente intercambiáveis e substituíveis, para atender à produção global. As escolas servem como locais para fundição e refino dos recursos humanos. Assim como nós rentabilizamos os recursos metálicos para garantir um sistema monetário padronizado para a fácil circulação de riqueza, também padronizamos os seres humanos para a fácil circulação do trabalho humano. A rentabilização de metais facilita o intercâmbio de produtos. A padronização de recursos humanos faz o mesmo. É claro que podemos tratar o próprio dinheiro como um produto, e é por isso que estabelecemos mercados de produtos que definem os padróes de troca. $\mathrm{O}$ mercado de trabalho trata as pessoas da mesma maneira. As pessoas frequentemente procuram aperfeiçoar-se como recursos humanos, obtendo graus educacionais que aumentam o valor do trabalho que é trocado por dinheiro, produtos, e assim por diante. Quando as escolas desempenham a funçáo de aperfeiçoar os recursos humanos adequadamente, aumenta-se o capital humano de uma nação.

Para aqueles que valorizam o individualismo democrático socialmente responsável, a padronização exigida pela lógica da teoria do capital humano e dos recursos humanos leva a uma deseducação maliciosa. É uma profunda ameaça a qualquer ideia de democracia vibrante e criativa. Eu pretendo mostrar que a padronizaçáo pressupóe noçóes de mesmice que degradam as ideias democráticas de igualdade, individualidade e liberdade de expressão que elas supostamente apoiam. É uma boa instância de conceitos e estruturas de negócios, reificados, burocráticos e tecnocráticos. Isso leva ao que eu 
Educ. foco, Juiz de Fora, v. 20 , n. 1 , p. $55-82$, mar. 2015 / jun. 2015 chamo de "o novo feudalismo estrutural". O feudalismo atual funde o pensamento de sistemas burocráticos e o capitalismo contemporâneo a estruturas sociais feudais. A situação real é muito mais complexa, mas essa ideia servirá suficientemente bem aos nossos propósitos.

$\mathrm{O}$ antigo feudalismo baseava-se no direito à terra e não se ocupava muito com a troca de produtos. É óbvio que o novo feudalismo não compartilha dessas premissas. As coisas poderiam ser melhores se ele compartilhasse, uma vez que o antigo feudalismo pelo menos fornecia bens comuns essenciais, enquanto o novo feudalismo busca cercar e privatizar a esfera pública. $\mathrm{O}$ novo feudalismo estrutural pressupóe que podemos refinar e tornar tudo, incluindo as pessoas, adequado para circular como um produto. $\mathrm{O}$ feudalismo medieval pressupunha uma ordem militar, econômica, sacerdotal e política predeterminada, fixa, hierárquica e final, que ninguém, de cima a baixo, poderia alterar. $\mathrm{O}$ novo feudalismo estrutural estabelece uma ordem social semelhante em que os participantes entendem que a alteração do que foi estabelecido é imoral, uma violaçáo da lei de Deus, da lei natural, ou de ambas. ${ }^{3}$ Em vez do direito divino dos reis ungidos por Deus, temos o direito divino da elite capitalista ungida pelo mercado. Os atuais gestores do dinheiro interpretam a vontade do mercado para os capitalistas ricos, tanto quanto o sacerdote de outrora interpretava a vontade de Deus para o príncipe. ${ }^{4}$ Enquanto isso, os militares protegem o mercado, do mesmo modo que o cavaleiro medieval defendia as propriedades dos senhores feudais.

3 Um esboço anterior da famosa advertência do presidente Eisenhower sobre o complexo militar-industrial e sua influência na política e no governo também deu nome à academia. Um complexo militar-industrial-acadêmico hierárquico semeado em conjunto por conceitos mundiais de sistemas corresponde muito bem à estrutura medieval de uma ordem militar, econômica e sacerdotal. Hoje, a ordem econômica é capitalista e os sacerdotes são acadêmicos, mas os fundamentos continuam os mesmos. 
O novo feudalismo estrutural beneficia principalmente a nova aristocracia, os capitalistas ricos. Eu poderia facilmente chamá-la de "dinheirocracia". ${ }^{5}$ No novo feudalismo estrutural, as escolas assumem a tarefa de padronizar o capital humano como um produto adequado para a troca imediata e que se encaixa passivamente na ordem sócio-político-econômica existente, em vez de indivíduos democráticos encarregados de desafiar e mudar o status quo. O novo feudalismo estrutural pode ainda derrotar o sonho da democracia expansiva continuamente criativa, deixando todos os ideais ideológicos da democracia no lugar, embora esvaziados de seu significado democrático. Uma maneira para fazer isso é reduzir a noção de igualdade moral à padronizaçáo e mesmice, fazendo, desse modo, uma paródia da individualidade genuína como uma autoexpressão criativa.

Meu artigo encontra inspiração em três ensaios curtos de John Dewey. Os dois primeiros, "Mediocrity and Individuality" (Mediocridade e individualidade) e "Individuality, Equality, and Superiority" (Individualidade, igualdade e superioridade), surgiram em 1922 em sucessivas ediçóes da revista The New Republic, da qual Dewey foi um colaborador regular durante muitos anos. Dewey acreditava que só tínhamos assegurado as condiçóes para a democracia, razão pela qual ele criticava os fundamentos do liberalismo moderno. Ele rejeitou o conceito de indivíduo atomístico desprovido de influências sociais. Em vez disso, comprometeu-se com a construção sociocultural de mentes e de indivíduos. Ele também rejeitou as noçōes de

5 É interessante que a palavra "moneyocracy" (dinheirocracia) aparece no Oxford Dictionary of the English Language (OED), mas não aparece no MerriamWebster. Esse termo do século XIX merece revitalização no século XXI. Um dos revisores desta revista sugeriu que eu deveria usar a palavra "cleptocracia" de forma mais precisa, o que o OED define como "um corpo governante ou ordem de ladrōes”. Esse revisor também sugeriu que cleptocracia em nossa nação significa que o governo está se apossando das escolas públicas e de outros bens e recursos públicos, a fim de entregá-los ao setor privado. A ideia geral é que o governo não é nem para as pessoas nem mesmo pelas pessoas. Isso me parece bastante provável. Gostaria apenas de acrescentar que a plutocracia e a oligarquia podem se juntar com a "dinheirocracia" e a cleptocracia de variadas maneiras complexas.

Juiz de Fora

v. 20 , n. 1 , 
racionalidade inata e de livre arbítrio inato. $\mathrm{O}$ terceiro ensaio, "Creative Democracy-The Task Before Us" (Democracia criativa: a tarefa que temos pela frente), foi lido na festa do octogésimo aniversário de Dewey, em Nova York, com a presença de cerca de 1.000 pessoas e na ausência do sempre tímido Dewey. $\mathrm{O}$ artigo é uma manifestação concisa do sonho de Dewey com uma sociedade mais democrática. Ele pensava que a democracia deveria constantemente recriar a si mesma, o que exige educar pessoas criativas únicas que constantemente reconstroem a sociedade, em vez de simplesmente se adequarem à ordem social existente. Todos os três artigos argumentam contra a ideia da igualdade democrática como significado de mesmice e padronização, o que, para Dewey, tornava a individualidade genuína uma farsa.

O novo feudalismo estrutural é uma corrupção do espírito democrático de liberdade e individualidade. Podemos localizar as sementes dessa degradação em forças presentes já nos conceitos que cercam a noção iluminista de indivíduo atomístico. O ideal era que cada pessoa "normal" nascesse com ambos, razão inata e livre arbítrio inato. Havia uma catástrofe oculta nesses dois pressupostos. A ironia, uma das muitas que encontraremos, é que se todos usassem sua razão inata corretamente e exercitassem a sua vontade de acordo com seus preceitos, então todos tomariam a mesma decisão e agiriam da mesma forma em situaçóes idênticas ou semelhantes. Aqueles que não fizessem assim seriam cognitivamente anormais ou moralmente baixos.

O novo feudalismo incorpora os ideais iluministas da democracia liberal, da qual os neoliberais constantemente dependem para derrotar todas as aspiraçóes por uma democracia mais profunda. $\mathrm{O}$ pensamento utilitário ajuda a reduzir a racionalidade a uma racionalidade simplesmente instrumental e calculista. Do mesmo modo, a ideia de criatividade tornauma ordem econômica fixa estranhamente feudal. Essa pseudodemocracia econômica pode facilmente derrotar 
a democracia social e política, bem como a democracia econômica genuína. Muitos educadores contemporâneos pensam que as ideias de Dewey sobre educação democrática são apenas progressismo impróprio, obsoleto para a era pósindustrial, pós-moderna ou talvez transmoderna de hoje. A ironia é que, para ele, ainda temos de alcançá-la.

A crítica ao individualismo iluminista e a defesa de noções de individualidade construtivistas socioculturais mais iluministas, tal qual feitas por Dewey, ressoam ao longo de seus escritos, desde a década de 1890 até a sua morte, em 1952. A visão crítica de Dewey é que não nascemos com a racionalidade, o livre arbítrio, com um eu ou uma mente. Devido à falta de espaço para fornecer detalhes, vamos nos contentar com duas declaraçóes simples de sua posição. Dewey observa: "A individualidade é um dado original apenas no sentido físico de corpos físicos em que os sentidos são separados. Em um sentido social e moral, a individualidade é algo a ser construído" (MW 12: 191). Em outra parte, ele afirma: "A liberdade ou individualidade, em suma, não é uma posse ou dom original. É algo a ser alcançado, a ser construído" (LW 2: 62). Alcançar a individualidade é assim tão importante para Dewey porque: “Toda invenção, toda melhoria na arte tecnológica, militar e política tem sua gênese na observaçáo e na ingenuidade de um inovador particular" (LW 1: 164). Dewey coloca "ênfase na individualidade como o fator criativo nas experiências da vida" (LW 15: 315). Ele dedicou livros inteiros para defender essas reivindicaçóes. Seu ataque contra o individualismo atomístico e a noção de que nascemos com nada mais do que instintos vagos biologicamente inatos tem implicaçóes óbvias em seu pensamento sobre a democracia, pela simples razão de que as ideias iluministas fundamentais empregadas na fundação da democracia "americana" são todas falsas. É por isso que ele declara no segundo parágrafo de "Creative Democracy-The Task Before Us" (Democracia criativa: a tarefa que temos pela frente) que essa democracia que temos foi "produto de condiçóes favoráveis que agora 
Jim Garrison

têm de ser vencidas por um esforço consciente e resoluto" (MW 13: 295). A tarefa que temos pela frente exige recriar a própria ideia de democracia e de indivíduo democrático. Eu acredito que isso também envolve repensar a ideia e o ideal de igualdade democrática.

Talvez a maior barreira para reconceber a democracia esteja no fato de que simplesmente assumimos que a democracia deu certo desde o início e que já temos toda a democracia de que precisamos. Dewey declara:

Se eu enfatizo que a tarefa só pode ser realizada pelo esforço inventivo e pela atividade criativa, em parte é porque a profundidade da crise atual deve-se consideravelmente ao fato de que, por um longo período, agimos como se a nossa democracia fosse algo que se perpetuou automaticamente; como se os nossos antepassados tivessem conseguido criar uma máquina que solucionasse o problema do movimento perpétuo na política. (225)

Para realizar a tarefa que temos pela frente, precisamos de cidadãos democráticos genuinamente criativos, que a padronização nunca possa alcançar.

Para compreender de que modo a padronização captura e constrange o pensamento educacional sobre a igualdade, a democracia e o indivíduo democrático, vejamos o No Child Left Behind Act (NCLB) aprovado em 2001 com massivo apoio bipartidário. ${ }^{6}$ Essa é a legislação federal mais recente que decreta uma reforma escolar baseada em padróes, fundamentada na teoria de que a definição de altos padróes e o estabelecimento de resultados mensuráveis melhorará a escolarização na América. O NCLB obriga os estados a desenvolverem padrốes de aprendizagem (SOL) e avaliaçóes

6 O No Child Left Behind controla a educação pública nos Estados Unidos, mas, por ser direcionado para a economia global, seus padrões são comuns em todo o mundo desenvolvido e em desenvolvimento. 
padronizadas em competências básicas para todos os estudantes, em graus especificados, para que recebam financiamento federal. Essas avaliaçôes dependem quase exclusivamente de testes padronizados de desempenho referenciados pela norma. Os currículos devem estar alinhados com esses testes, cabendo aos professores ministrá-los e aos administradores, forçarem o seu cumprimento. As escolas que ficam abaixo do padráo são punidas. Trata-se de um exemplo quase perfeito do pensamento mundial de sistemas inspirados em negócios.

Alguém pode se opor aos altos padróes, aos objetivos padronizados claramente definidos e aos resultados medidos por testes padronizados? Alguém acha que não devemos responsabilizar estudantes, professores e escolas por esses padróes? Existe alguém que, sendo comprometido com o tratamento democrático, justo e igual para todas as crianças, poderia se opor? John Dewey, ele é esse alguém.

O nome de Dewey raramente surge em minhas aulas. Em vez disso, quando nos voltamos para as questóes de igualdade, igualdade de oportunidades e justiça social, eu invoco o poeta William Blake (1793/1988), que escreve: "A mesma lei para o leão e para o boi é opressão" (44). Eu pretendo que meus alunos-professores considerem a possibilidade de que igualdade democrática não significa mesmice e padronização. Eu entáo peço a eles para nomear algo que fazem muito bem. Alguns se sobressaem em matemática, alguns no atletismo e outros nas artes ou nas ciências. Alguns falam de habilidades sociais e de fazer amigos. Com uma central de estagiários no campus, não é raro alguém mencionar as habilidades e a qualidade de caráter necessárias para a soldagem. A Future Farmers of America foi fundada em minha universidade (Virginia Tech) e temos lá um departamento de educação profissional altamente qualificado; por isso muitas vezes eu recebo como resposta habilidades em pecuária, agricultura, conservação da terra 
Garrison

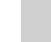

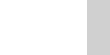

(1)

e máquinas ${ }^{7}$. Os estudantes sempre se surpreendem não só com a diversidade, mas também com a intensidade com que uma pessoa pode desgostar profundamente de algo que outra pessoa aprecia com paixão. Nós geralmente concordamos que o mau desempenho em alguma coisa específica, ou uma série de coisas, não quer dizer que alguém é estúpido ou sem dons. Eventualmente, nós começamos a falar sobre como até mesmo indivíduos que são bons na mesma coisa a fazem com estilos diferentes. Os graduandos em música muitas vezes continuam esta conversa. Nós geralmente nos voltamos para a diferença entre áreas temáticas, diferentes estilos de ensino e de aprendizagem e as expectativas de meus alunos-professores em relação à autonomia criativa e à autoexpressão em sala de aula. Eu costumo perguntar quantos deles podem nomear as três máquinas simples que estão nos testes padronizados para passar no terceiro ano em Virgínia. Eventualmente, muitos concordam que náo é democrático buscar a igualdade por meio da padronização e da mesmice.

A igualdade democrática executada como mesmice é uma paródia do que as nossas naçóes requerem para abraçar a individualidade forte e os ideais democráticos. A filosofia da educação de Dewey nos mostra por quê. Em "Creative Democracy - The Task Before Us" (Democracia criativa: a tarefa que temos pela frente), Dewey afirma que a busca pela democracia está longe de ser concluída. Hoje, a nossa tarefa é garantir à democracia, com inteligência, apenas a boa sorte que nos foi prometida no começo. Para fazer isso corretamente, devemos recriá-la artisticamente:

Em todos os casos, é isso o que quero dizer quando digo que agora temos de recriar, pelo esforço deliberado e determinado, o tipo de democracia que, em sua origem há 150 anos, foi em grande parte o produto de uma combinaçáo feliz de homens e circunstâncias.

7 Fundada em 1928, a Future Farms of America é uma organização destinada à educação agrícola (Nota do Editor). 
Temos vivido por um longo tempo sobre a herança que nos veio da conjunção feliz de homens e eventos em uma época anterior. O estado atual do mundo é mais do que uma lembrança de que temos agora de levar adiante toda a nossa energia para provar que somos dignos de nossa herança. (LW 14: 225)

A tarefa que temos pela frente requer ainda mais energia do que a que foi exigida na época de Dewey. Grande parte da tarefa nas escolas e no restante da sociedade envolve superar as concepçóes culturalmente arraigadas das principais ideias democráticas, como "igualdade", que foram mal formadas desde o início. Nossa herança proporciona oportunidades e obstáculos. Meu artigo é uma tentativa de começar a repensar artisticamente a mesma ideia de igualdade democrática como parte do projeto maior de reconstruir a democracia para os nossos tempos.

Dewey passa a enfatizar que "a tarefa só pode ser realizada por meio de esforço inventivo e criatividade" (225). Somente a liberação do potencial criativo individual pode cumprir tais objetivos:

A fé democrática na igualdade humana é a crença de que todo ser humano, independentemente da quantidade ou do alcance de seus dons pessoais, tem direito à igualdade de oportunidades, como qualquer outra pessoa, para o desenvolvimento de qualquer dom que ele possua. A crença democrática no princípio da liderança é generosa. É universal. (226-227)

Dewey tem mais fé na individualidade humana do que os políticos e os especialistas de hoje jamais tiveram em seus discursos patrióticos. O que ele afirma não é que cada indivíduo deva ter oportunidade igual de tomar o seu lugar na ordem social existente, muito menos que devamos tratar a todos exatamente segundo os mesmos padrôes. Esse é o objetivo do NCLB, que contribui para o novo feudalismo estrutural. Em
Individualidade e Igualdade como chaves para a democracia criativa 
vez disso, ele afirma que cada indivíduo tem o direito de ter seu potencial único concretizado em toda a extensão possível; que cada indivíduo pode dar a sua contribuição única não apenas para preservar, mas também para melhorar a sociedade, trazendo a sua voz única para o diálogo público. ${ }^{8}$

Dewey quer repensar o discurso dominante sobre a igualdade. Para ele, a igualdade, pelo menos a igualdade moral, não significa mesmice. Também não significa oportunidade igual para se tornar aperfeiçoado como uma parte padronizada, intercambiável e substituível, escolarizada com o intuito de se adequar a um papel predeterminado na função de produção existente. Ele enfatiza a singularidade, a diferença e a impossibilidade de substituição. Devemos louvar a individualidade genuína e a autoexpressão responsável. Dewey nos impulsiona a perceber que:

a democracia é uma forma pessoal de vida individual; ela significa a posse e o uso contínuo de determinadas atitudes, formando o caráter pessoal e determinando o desejo e o propósito em todas as relaçôes da vida. Em vez de pensar em nossas próprias disposiçóes e hábitos como adaptados a certas instituições, temos de aprender a pensar nas instituiçôes como expressóes, projeçôes e extensôes de atitudes pessoais habitualmente dominantes. (226)

Dewey salienta a liberação do potencial criativo humano para preservar, transformar e melhorar a sociedade. Cada um de nós é uma singularidade, com necessidades especiais próprias, desejos, interesses, consciências, propósitos e projetos. Cada um é capaz de realizar o papel de líder, dependendo da ocasiáo e de seus talentos particulares. Para pensar assim, devemos deixar de acreditar que liderança significa governo por um grupo de elite de especialistas. Em vez disso, devemos buscar

8 De maneira significativa, muitos dicionários definem "único" em termos de não haver um semelhante ou igual. 
o governo não só para o, mas também pelo povo. Devemos buscar a igualdade moral, e não a física ou mental.

A interpretação da igualdade como mesmice destrói a igualdade moral, o desenvolvimento da individualidade e, a um só tempo, a liberação do potencial criativo único para realizar a tarefa de recriar nossa democracia. Isso leva à noção de que a igualdade de oportunidades significa que todos têm o direito de competir por um lugar desejável em uma estrutura social preestabelecida. Reduz o ideal de igualdade de oportunidades educacionais a objetivos curriculares padronizados, a um currículo padronizado e às determinaçóes de testes padronizados, nenhum dos quais pode reconhecer a possibilidade humana única. O problema do NCLB é a sua concepção padronizada de igualdade de oportunidades educacionais. ${ }^{9}$ Ele passivamente adapta o indivíduo a instituiçóes já existentes, especialmente a instituiçóes econômicas. $\mathrm{O}$ resultado é a conformidade social do novo feudalismo estrutural, em vez da democracia criativa.

Para perceber o que está errado com a padronização, vamos considerar os dois ensaios da revista The New Republic mencionados anteriormente. Eles deveriam ser reimpressos hoje, uma vez que são mais relevantes do que nunca. $\mathrm{O}$ parágrafo de abertura de "Mediocrity and Individuality" (Mediocridade e individualidade) aborda a ambiguidade da palavra "individualismo". Dewey conclui:

Individualidade é a palavra mais certa; ela carrega consigo uma conotaçấo de exclusividade de qualidade ou pelo menos de distinçáo. Ela sugere uma liberdade que não é legal, nem comparativa nem externa, mas que é intrínseca e construtiva. Nossos antepassados,

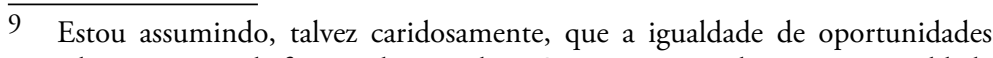
educacionais é, de fato, o objetivo do NCLB. Eu concordaria com a igualdade de oportunidades educacionais e com a igualdade como mesmice, se isto significasse que cada indivíduo único tem o mesmo direito (igual) de ter seu potencial único concretizado. No entanto, estou certo de que a padronizaçáo do que se designa como "realizaçáo" está entre os objetivos do NCLB, por isso eu não acredito que o NCLB (ou o NCATE etc.) possa buscar a igualdade de oportunidades educacionais para alcançar a igualdade moral.

Educ. foco, Juiz de Fora v. 20 , n. 1 , mar. 2015 / jun. 2015 


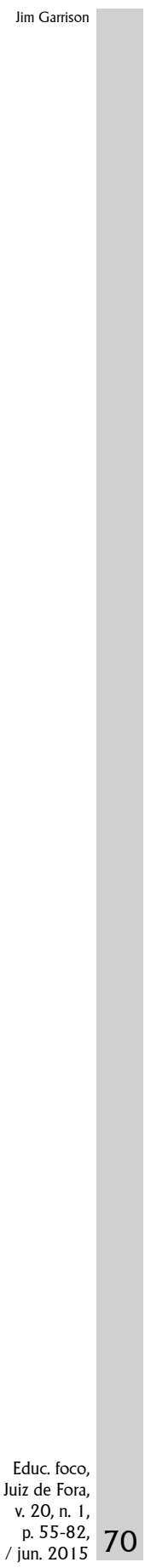

que permitiram o crescimento de arranjos jurídicos e econômicos, pelo menos supunham, mas erroneamente, que as instituiçôes que eles favoreciam iriam desenvolver a individualidade pessoal e moral. Reservou-se para a nossa própria época combinar, sob o nome de individualismo, o louvor da energia egoísta referente à realizaçáo industrial com a insistência sobre a uniformidade e a conformidade, no que se refere à mente. (MW 13: 289)

Dewey exalta e defende a individualidade como singularidade qualitativa, e não como construçóes quantitativas jurídicas de negócios, da indústria ou do governo. Ele está preocupado com o indivíduo moral, criativo, expressivo, e não com capital humano. $\mathrm{Na}$ passagem citada, nota-se que Dewey acredita, ao mesmo tempo, que eventos subsequentes nos Estados Unidos degradaram a ideia indispensável do individualismo e que nossos antepassados também permitiram, equivocadamente, o crescimento de formas de individualismo que não contribuíram para o individualismo democrático genuíno, embora as suas intençôes talvez fossem as melhores. A vida é repleta de tragédias (e comédias) de consequências inesperadas. Em nenhum lugar essa observação é mais verdadeira do que no campo da educação.

Dewey mostra estar completamente ciente dos perigos de uma democracia que eventualmente erradica toda distinção e submerge a individualidade na conformidade ideológica irrefletida:

Agora que chegamos ao ponto de reverência à mediocridade, por submersáo da individualidade em ideais e credos em massa, talvez não nos surpreenda que, depois de ostentar por um longo tempo que não tínhamos classes, agora nós nos vangloriamos de ter descoberto um modo científico de dividir nossa populaçáo em classes definidas. Assim como Aristóteles racionalizou a escravidáo, mostrando que para os que eram naturalmente superiores era natural constituírem os fins 
para os outros que eram apenas ferramentas, nós também, enquanto nos maravilhamos talvez com a insensibilidade do filósofo grego, racionalizamos as desigualdades $\mathrm{da}$ nossa ordem social, apelando para estratos psicológicos inatos e imutáveis na população. (289)

Devemos evitar a reificação; isto é, naturalizar as relaçóes sociais contingentes como se fossem necessárias e, depois, utilizar os resultados para racionalizar a injustiça. Dewey está plenamente consciente dos perigos apontados pelos críticos conservadores da democracia para as massas. Ele próprio é um defensor da aristocracia, mas não do tipo que esses críticos elogiam. Sua forma de aristocracia não suprime a distinção e a diferença em noçóes falsas de igualdade, padronização e mesmice.

Outro problema dos testes padronizados é que eles não dizem nada sobre os indivíduos particulares que procuramos educar. Por exemplo, eles nos deixam ignorantes acerca da habilidade única ou da realização distintiva. Não admira que não eduquemos para isso. Dewey pergunta: "Mas por que foi táo geralmente assumido entre os nossos líderes cultivados que uma fórmula puramente classificatória forneceria informações sobre a inteligência individual na sua individualidade?” (290-291). ${ }^{10}$ As necessidades, desejos e interesses específicos, juntamente com o desenvolvimento cognitivo moral e artístico, dão a cada indivíduo uma perspectiva única sobre a existência, e, portanto, a capacidade única de oferecer uma contribuição única. Dewey responde a sua própria pergunta desta forma:

10 Em parte, Dewey está pensando em inteligência no seu sentido etimológico. Ou seja, "inter" (entre, dentre) e "legere", escolher. Ele também pode estar pensando em termos da antiga noção de gênio como possessão divina ou um demônio pessoal. Se ele não estava de fato pensando assim, isso não nos impede de fazer isso nós mesmos. Dewey era um naturalista. Podemos pensar em "possessão divina", como ser possuído por ideais que norteiam a nossa conduta. Encontramos esse ideal no discurso do Reverendo Martin Luther King: "Eu tenho um sonho".

Educ. foco, Juiz de Fora v. 20 , n. 1 , 
Estamos irremediavelmente acostumados a pensar em médias padronizadas. Nosso ambiente econômico e político nos leva a pensar em termos de classes, agregados e membros submersos neles. Apesar de toda a nossa conversa sobre a individualidade e o individualismo, não temos o hábito de pensar em termos de qualidades distintivas, muito menos exclusivamente individualizadas.

O costume cultural e político profundamente estabelecido de pensar apenas em termos de padróes, combinado com uma falsa sensaçáo do que a estatística pode alcançar, tem efeitos devastadores nas nossas deliberaçóes sobre o indivíduo democrático e a educação democrática. Essa falta de consciência reflexiva está por trás do NCLB e representa muito de sua eficiência vulgar destrutiva.

$\mathrm{O}$ alvo específico de Dewey em "Mediocrity and Individuality" (Mediocridade e individualidade) é o teste de inteligência, que compreende a primeira onda de uma cascata que varreu qualquer preocupaçáo com a personalidade individual na escolarização. Sobre esses testes, ele salienta: "Um Q.I., como determinado na atualidade, é no máximo uma indicação de certos riscos e probabilidades. Seu valor prático reside no estímulo que dá à investigação mais íntima e intensa de habilidades e incapacidades individualizadas" (293). Eles ainda são determinados dessa maneira. O problema com todos esses testes é que "a qualidade da individualidade lhes escapa” (292). Dewey elabora um exemplo bem construído do que ele quer dizer: "O seguro de vida torna-se impossível, por exemplo, sem extensas investigaçóes estatísticas, estabelecendo normas médias quantitativas. Os indivíduos são classificados de acordo com o seu grau de risco segurável, com base nessas normas. Mas ninguém supóe que o resultado determine o destino de qualquer pessoa específica” (292-293). Infelizmente, os testes de desempenho reificam, de fato, suas construçóes e selam o destino de milhóes de pessoas quando usados como dispositivos de controle de acesso. 
Dewey percebe que os testes padronizados são melhores para determinar se um indivíduo possui as aptidóes e realizaçôes mais úteis para se adequar a papeis pré-instituídos no novo feudalismo estrutural. Sabemos há tanto tempo que esses testes incorporam os preconceitos das classes dominantes, que universalizam e reificam suas ideologias e interesses de muitas maneiras (gênero, raça, meio cultural etc.), que quase desistimos de falar sobre isso. Esses testes também podem oprimir o desenvolvimento da individualidade genuína, firmando o sucesso social de um conjunto relativamente pequeno de atributos aprovados pelas classes aristocráticas e afastando atributos que, liberando potenciais únicos, podem ameaçar as estruturas de poder existentes. Isso nos proíbe de educar indivíduos genuínos que podem ver a recriação de uma rica democracia cívica e política como a tarefa que eles têm pela frente na vida.

$\mathrm{Na}$ edição seguinte da The New Republic, Dewey reitera, aprofunda e desenvolve seu pensamento em "Individuality, Equality and Superiority" (Individualidade, igualdade e superioridade). Dewey dedica seu segundo ensaio a um "reexame das ideias fundamentais da superioridade e da igualdade" (295). O parágrafo de abertura ataca a noção de igualdade como medida padronizada, declarando:

\begin{abstract}
os resultados de testes mentais provam até que ponto nos é permitido julgar e tratar os indivíduos não como indivíduos, mas como criaturas de uma classe, uma classe quantitativa que abrange características verdadeiramente individualizadas. . . . "Iguais" são aqueles que pertencem a uma classe formada por chances semelhantes de obter reconhecimento, posição e riqueza na sociedade atual. (MW 13: 295)
\end{abstract}

Essas classes quantitativas classificam os estudantes em classes sociais predeterminadas, educando para o destino 


\begin{abstract}
Jim Garrison
provável. ${ }^{11}$ Em vez de classificar e adaptar as habilidades físicas e mentais, a disposição e os hábitos às instituiçóes econômicas, governamentais e religiosas da sociedade atual, uma educaçáo democrática afirmaria a igualdade moral qualitativa em prol da concretizaçáo do potencial humano único de recriar a sociedade.

De forma pragmática típica, Dewey comenta que há "tantos modos de superioridade e de inferioridade quanto consequências a serem alcançadas, e trabalhos a serem realizados... Mas a ideia de superioridade abstrata universal é um absurdo" (226). O problema com os nossos objetivos, currículos e testes padronizados é que eles examinam apenas um conjunto muito pequeno de habilidades cognitivas e realizaçóes, ignorando
\end{abstract}

11 Em Democracy and Education (Democracia e educação) (MW 9), Dewey escreve: "A educaçáo através de ocupaçóes combina consequentemente entre si mais fatores favoráveis à aprendizagem do que qualquer aprendizagem, por qualquer outro método" (MW 9: 319). No entanto, ele rejeita a educação para uma ocupação (educação profissional) em escolas públicas. Isso deve vir mais tarde e à custa dos negócios e da indústria, em vez de à custa dos cidadãos. Em um ensaio intitulado "Education vs. Trade-Training" (Educação x capacitação profissional), que surgiu em 1915, ele respondeu à declaração de Snedden, dizendo: "Oponho-me a considerar como educação profissional qualquer treinamento que não tenha como atençáo suprema o desenvolvimento dessa iniciativa inteligente, da ingenuidade e da capacidade executiva, que, tanto quanto possível, podem tornar os trabalhadores donos do seu próprio destino industrial. Eu tenho minhas dúvidas sobre a predestinação teológica, mas absolutamente em todos os eventos em que o dogma atribuiu poder de predestinação a um ser onisciente; e eu sou totalmente contra atribuir o poder de predestinação social, por meio da capacitação profissional restrita, a qualquer grupo de homens falíveis, não importa quão bem intencionados eles sejam". (MW 8: 411)

Dewey compreendeu o calvinismo capitalista implícito na ideia de rastreamento. Esse pensamento permanece ativo atualmente no NCLB. Perto do fim de sua resposta a Snedden, Dewey concluiu irônico: "Infelizmente, eu sou forçado a concluir que a diferença entre nós não é tão estritamente educacional quanto é profundamente política e social. $\mathrm{O}$ tipo de educação profissional em que estou interessado não é a que 'adaptará os trabalhadores ao regime industrial existente; eu não sou suficientemente apaixonado pelo regime, para isso. Parece-me que a tarefa de todos os que não são servos da rotina educacional é resistir a cada movimento nesta direção e lutar por um tipo de educação profissional que mudará primeiro o sistema industrial existente e, finalmente, o transformará”. (MW 8: 412)

Juiz de Fora,

v. 20, n. 1 , 
muitas habilidades e disposiçôes morais e estéticas valiosas. Enquanto isso, a cultura requer a realização de uma variedade de trabalho infindável e potencialmente em expansão. Isso significa que precisamos de capacidades distintivas não apenas para executar com criatividade funçóes sociais pré-existentes, mas também para modificá-las, enquanto inventamos novas. Em vez disso, queremos preservar o novo feudalismo estrutural:

Quando as classificaçóes são rígidas, a fase mais ou menos quantitativa da superioridade é inevitavelmente notável. As castas são classificaçôes ou graus de superioridade; dentro de cada casta, a ordem hierárquica maior e menor é repetida... É uma prova da influência ainda exercida sobre nós pelos arranjos feudais. Nosso novo feudalismo da vida industrial, que classifica desde o grande financiador, passa pelo capitâo da indústria até o trabalhador não qualificado, revive e reforça a disposiçáo feudal de ignorar a capacidade individual que se manifesta em buscas livres ou individualizadas. (296)

O novo feudalismo estrutural da vida industrial, agora pósindustrial, ainda pode derrotar o velho sonho de relaçóes sociais democráticas. Ele certamente está derrotando o individualismo democrático nas escolas públicas de nossa nação.

Desde Nation at Risk (Uma nação em risco), em 1983, a retórica da reforma da escola pública concentra-se na competição econômica global. Líderes empresariais e políticos superam em muito os educadores nas cúpulas nacionais de escolarização mais influentes. Tudo que você tem de fazer é ouvir atentamente o discurso público sobre a escolarização. Nós estamos constantemente falando sobre economia, seja sobre a recessão atual ou sobre os tempos áureos da década de 1990. Na verdade, o vocabulário da eficiência dos negócios, da competitividade, da teoria do capital humano e da padronização permeia todo tipo de conversa pública, mesmo na religiáo, em que a ética do trabalho protestante ainda prevalece. 
No interior do novo feudalismo estrutural, as pessoas são valorizadas segundo a posição que ocupam em uma hierarquia final predestinada, supostamente fixa, que assume que algumas pessoas não só nasceram cognitiva e fisicamente superiores a outras, mas também, no caso do calvinismo capitalista, moralmente superiores. Dewey deseja repensar a superioridade e a inferioridade em termos de um modelo funcionalista mais orgânico:

Algumas vezes, em teoria, nós concebemos toda forma de atividade útil como nivelada com todas as demais, desde que realmente marquem o desempenho do serviço necessário. Nesses momentos, também reconhecemos, pelo menos em tese, que há um número infinito de formas de ação significativa. (MW 13: 296)

Dewey deseja transmitir uma ideia importante, referente ao funcionamento tanto dos corpos orgânicos quanto do corpo político. Para que o corpo humano funcione bem, toda subfunção também deve funcionar bem. Há a tendência de colocar o cérebro acima de todas as outras funçóes do corpo. $\mathrm{Na}$ verdade, muitas vezes fazemos a separação entre a função executiva do cérebro e o corpo, reproduzindo assim o velho dualismo entre mente e corpo. No entanto, se os intestinos não funcionarem bem, o cérebro também não funcionará bem. $\mathrm{O}$ mesmo vale para qualquer outra função orgânica. $\mathrm{O}$ darwiniano Dewey sabia muito bem que, se qualquer função é necessária para a sobrevivência e a reprodução biológicas, então ela é necessária e valiosa como qualquer outra função. $\mathrm{O}$ mesmo vale para qualquer sociedade que busca não apenas se preservar e se reproduzir, mas também crescer. Um dia, em minha classe, um aluno-professor lembrou-nos que os lixeiros seriam sempre necessários. Eu respondi que, se realmente precisamos desses homens e mulheres para manter uma sociedade saudável, então devemos honrá-los, respeitá-los e pagar-lhes bem. 
Quando entendermos que a estrutura orgânica de uma sociedade viva deve transformar-se para adaptar-se a um mundo em mudança, perceberemos o valor da igualdade moral. A passagem a seguir começa com uma requintada reformulação do ideal de igualdade moral, enquanto o restante poderia servir como uma descriçáo precisa do No Child Left Behind:

Pelo menos alguns supuseram, certa vez, que o propósito da educação, juntamente com o oferecimento de algumas ferramentas indispensáveis aos estudantes, era descobrir e liberar capacidades individualizadas para que eles pudessem trilhar seus próprios caminhos, qualquer que seja a mudança social envolvida em sua operaçáo. Mas agora damos boas-vindas a um procedimento que, sob o título de ciência, afunda o indivíduo em uma classe numérica; julga-o com referência à capacidade de adequarsea um número limitado de vocaçóes classificadas de acordo com os padróes de negócios atuais; destina-o a um nicho predestinado e, desse modo, faz o que a educaçáo pode fazer para perpetuar a ordem atual. (297)

Dewey chega a expressar um sentimento de sarcasmo que é muito raro em seus escritos:

O lema das distinçôes genuinamente individuais é o do batalhăo de tanques de guerra. "Treat'em rough"12 - exceto quando eles prometem sucesso nesta ou naquela classificaçấo social estabelecida. Caso contrário, a pessoa pode crescer para ser um opositor consciente, ou um inovador social, ou ser propenso a exigir o reconhecimento social por atuar em uma investigaçáo científica livre, ou em artes, ou em alguma outra vocação luxuosa e ornamental. (297)

12 Treat’em rought, expressão que significa "trate-os de maneira rude", é o título de um romance escrito por Dale Wilson e de um filme dirigido por Ray Taylor, ambos tratando das campanhas da I Guerra Mundial em que foi decisivo o uso de tanques de guerra (Nota do Editor). 
Entre outras coisas, Dewey capta a ironia na retórica do chamado "amor rude", que normalmente é direcionado às minorias e aos pobres, uma vez que o eleito do capitalismo calvinista pode sobreviver na versão mais suave.

Em vez de padronização e mesmice, a filosofia de educação de Dewey enfatiza a diferença qualitativa incomensurável. Em "Creative Democracy-The Task Before Us," (Democracia criativa: a tarefa que temos pela frente), Dewey observa:

Cooperar, oferecendo às diferenças uma chance para se mostrarem, porque a crença de que a expressão da diferença não é apenas um direito das outras pessoas, mas também um meio de enriquecer a sua própria experiência de vida, é inerente à forma de vida pessoal democrática. (229)

Observe que Dewey está refletindo sobre as diferenças além das fronteiras dos direitos e da tolerância. Para ele, é metafísica. Em outra parte, ele comenta: "Em um dado momento, há potencialidades não concretizadas em um indivíduo porque, e na medida em que, existem outras coisas com as quais ele ainda náo interagiu" (LW 14: 109). Todo mundo sabe que, para Dewey, o objetivo da educação é o crescimento. Também deve ficar claro que ninguém faz isso sem ajuda. Exigimos que outros, diferentes de nós, cresçam e se desenvolvam. Dewey tem a fé de um democrata pluralista; os defensores conservadores declarados da aristocracia, não.

Nós perdemos o significado da palavra democracia, o qual Dewey insiste que reside na "fé na individualidade, nas qualidades exclusivamente distintivas em cada ser humano normal; a fé nos modos de atividade únicos correspondentes que criam novos fins, com a pronta aceitação das modificaçóes na ordem estabelecida, impostas pela liberaçáo das capacidades individualizadas" (LW 13: 297). Você mantém essa fé? Se assim for, espero que concorde que ela se estende além dos limites normalmente circunscritos pela palavra "normal". 
Segundo Dewey, se pudermos reafirmar a fé democrática na individualidade, podemos repensar a aristocracia:

Democracia, neste sentido, denota, podese dizer, a aristocracia levada ao seu limite. É uma afirmação de que todo ser humano como indivíduo pode ser o melhor para algum propósito específico e, portanto, ser o mais adequado para governar, liderar, nessa circunstância específica. O hábito de classificaçóes fixas e limitadas numericamente é inimigo tanto da aristocracia verdadeira quanto da democracia verdadeira. Como os nossos aristocratas declarados rendem-se tão alegremente ao hábito de classificaçôes quantitativas ou comparativas, é fácil detectar o esnobismo de maior ou menor refinamento, sob o seu declarado desejo por um regime de distinção. Pois somente o indivíduo é, em última análise, distintivo; o resto é uma questão de qualidades comuns, diferentes apenas em grau. (297-298)

Dewey prevê uma aristocracia de todos, composta por qualquer um que tenha preenchido seu potencial único, de tal modo que dê uma contribuiçáo criativa única para a comunidade.

Aqui está um exemplo desse aristocrata retirado de meus anos de trabalho com uma professora maravilhosa, Eva Stranger (um pseudônimo), em uma oficina de leitura e escrita do quarto ano. Na aula de Eva, durante duas horas por semana os alunos escreviam e compunham histórias. A cada seis semanas, eles "publicavam" uma história em um acervo da classe. Nessa sala de aula de habilidade mista totalmente inclusiva, alunos de todos os níveis escreviam boas histórias e corrigiam cuidadosamente a ortografia e a gramática. Não é difícil compreender por que, já que consideramos que todos nós ansiamos pela autoexpressão e todos queremos aparecer bem em público diante de nossos colegas. Muitas vezes, os alunos também liam histórias sentados na "cadeira dos

Educ. foco, Juiz de Fora v. 20 , n. 1 , mar. 2015 / jun. 2015 
Jim Garrison

autores”. Eva normalmente ocupava a cadeira de balanço, e todos entendiam que, quando um colega estava lendo uma história, o resto deveria prestar a mesma atenção e respeito que tinham por ela. Além disso, todo mundo queria que os outros os ouvissem quando eles liam. As coisas eram um pouco diferentes com Tom (um pseudônimo), que tinha síndrome de Down. Ele era o autor de suas histórias, e as explicava em detalhes com a ajuda de um professor. Quando chegava a hora de "ler" histórias, Tom sempre oferecia uma narrativa dramática; ele atuava na história, muitas vezes representando o papel de vários personagens. Ele não ficava inibido em suas apresentaçóes, e elas eram fascinantes. Quando era a vez de Tom contar histórias, havia uma atmosfera elétrica de excitação carnavalesca na classe. Gritos risonhos, muitas vezes tomados por forte emoção, acompanhavam cada apresentação. Crianças e adultos sempre aplaudiam as apresentaçóes freneticamente. Meu ponto é que, para os fins específicos da narrativa dramática, Tom foi o aristocrata nesta comunidade, isto é, o mais adequado para governar, para liderar. Quando perguntado se os modelos de educaçáo progressiva de Dewey podem realmente funcionar em sala de aula, eu sempre respondo que sim, porque eu já os vi funcionar.

Igualdade moral é a moral da minha história. É o que uma filosofia educacional democrática pode obter de você, se você tiver a imaginação moral para vê-la e a disposição moral para realizá-la. Dewey pensava que qualquer "defensor inteligente da igualdade democrática” poderia ver que:

a igualdade moral não pode ser concebida com base em arranjos jurídicos, políticos e econômicos. Todos esses são obrigados a ser classificatórios; a se preocuparem com uniformidades e médias estatísticas. A igualdade moral significa incomensurabilidade, a inaplicabilidade de padróes comuns e quantitativos. Isso significa qualidades intrínsecas que exigem diferenciada; superioridade em encontrar 
um trabalho específico para fazer, não no poder para alcançar objetivos comuns a uma classe de concorrentes, o que certamente resultará em colocar um prêmio no domínio sobre os outros. (299)

Os defensores inteligentes da igualdade democrática devem rejeitar padróes quantitativos fixos e inflexíveis e evitar quaisquer currículos ou padróes curriculares destinados a se alinhar com esses padróes, classificaçóes etc. Isso significa que devemos rejeitar o NCLB e atos semelhantes (por exemplo, o NCATE), em favor de modos de educação mais democráticos. Isso não é dizer que alguns padróes são incapazes de fornecer uma orientação fluida e flexível. Podemos nos reproduzir de maneira inteligente por meio da re-criação de nós mesmos, em vez da clonagem.

\section{REFERÊNCIAS}

BLAKE, William (1793/1988). The Marriage of Heaven and Hell. In The Complete Poetry and Prose of William Blake. New York, N. Y.: Anchor Books.

COX, Harvey. "The Market as God." The Atlantic Monthly. PAX, 1999. DEWEY, John. The Middle Works. Illinois: Southern Illinois University Press, 1991.

The Later Works. Illinois: Southern Illinois University Press, 1984.

[As citações das obras de Dewey são da edição crítica publicada pela Southern Illinois University Press. Os números de volume e página seguem as iniciais da série. As abreviaturas utilizadas para os volumes são: MW The Middle Works (1899-1924); LW The Later Works (1925-1953)]

Data de recebimento: novembro de 2013

Data de aceite: junho de 2014 